\title{
The Effects of Muscarinic Cholinergic Receptor Antagonist on Slow Bursting Neuronal Activity in the Rat Intergeniculate Leaflet*
}

\author{
Katarzyna WERHUN and Marian H. LEWANDOWSKI
}

Accepted April 20, 2009

\begin{abstract}
WERHUN K., LEWANDOWSKI M. H. 2009. The effects of muscarinic cholinergic receptor antagonist on slow bursting neuronal activity in the rat intergeniculate leaflet. Folia biol. (Kraków) 57: 187-192.

The intergeniculate leaflet (IGL) of the thalamus is an important neuronal element of the mammalian circadian time-keeping system. It receives direct input from retinal ganglion cells. In addition, there are, among other projections, afferents to the IGL from the brainstem cholinergic nuclei. The aim of the present study was to determine the influence of intravenous (i.v.) application of atropine - a muscarinic acetylcholine receptor antagonist, on the ultra-slow isoperiodic oscillations of the IGL neurons. Spontaneous neuronal activity was extracellularly recorded from the rat IGL. Different concentrations of atropine were administrated after recording baseline activity. In all experiments, the period of oscillation became longer after injection of atropine. In some of cases we also noted a temporary disturbance of the oscillatory pattern of neuronal activity. These data suggest that the oscillatory firing of IGL cells can be modulated by cholinergic influence.
\end{abstract}

Key words: Atropine, intergeniculate leaflet, intravenous, in vivo, mAChRs, ultradian oscillations.

Katarzyna WERHUN, Marian H. LEWANDOWSKI, Department of Neurophysiology and Chronobiology, Chair of Animal Physiology, Institute of Zoology, Jagiellonian University, R. Ingardena 6, 30-060 Krakow. Poland.

E-mail:lew@zuk.iz.uj.edu.pl

In mammals, the circadian time-keeping system (CTS) is established by two major neuronal structures: the suprachiasmatic nuclei (SCN) of the anterior hypothalamus and the intergeniculate leaflet (IGL), a distinctive subdivision of the lateral geniculate nucleus (LGN) of the thalamus (MOGA \& MOORE 1997; MOORE et al. 2002). Light is a principal zeitgeber that synchronizes circadian rhythms to the environmental light-dark (LD) cycle. Both mentioned structures receive direct input from retinal ganglion cells. Additionally, the IGL receives non-photic information and is responsible for the integration of this information with photic effects transmitted by the optic tract (WEBER \& REA 1997). The main neuronal pathways conveying non-photic information arrive from the origin of non-specific projection localized in the brain stem. Several anatomical, pharmacological and electrophysiological studies confirm the existence of such afferents to the intergeniculate leaflet from locus coeruleus (LC), dorsal raphe nuclei (DRN) (BLASIAK et al. 2006; MOORE \& CARD 1994) or brainstem cholinergic nuclei - mesopontine laterodorsal tegmental (LDTg) and pedunculpontine tegmental nuclei (PPTg) (BRAUER et al. 1984; HOROWITZ et al. 2004; LEVEY et al. 1987; PEKALA et al. 2007).

Considerable data support a role of cholinergic agents as regulators of the circadian system. Electrophysiological studies have shown that SCN neurons are responsive to the iontophoretical application of acetylcholine (ACh), both in vivo and in vitro (KOW \& PFAFF 1984). Also carbachol - an agonist of the cholinergic receptors, has been shown to shift the phase of circadian rhythms in rodents when administered intraventricularly or directly into the suprachiasmatic nucleus (BINA \& RUSAK 1996; LIU \& GILLETTE 1996). Moreover, nicotine administration induces c-Fos-like immunoreactivity in the SCN in a time- and dosedependent manner (FERGUSON et al. 1999).

Despite the well-studied role of acetylcholine in the circadian system, little is known about the functional significance of the connection between

\footnotetext{
*Supported by grant BW/IZ/10a from the Institute of Zoology of the Jagiellonian University.
} 
brainstem reticular formation and the IGL. Experiments with potentials evoked in the intergeniculate leaflet (by stimulating the contralateral SCN) and inhibition after LDTg stimulation (LEWANDOWSKI \& BLASIAK 1999) suggest that the activity of the IGL can be influenced by the cholinergic projection from LDTg. Moreover, recent results obtained by our group indicate the modulatory effect of carbachol on the glutamate-induced activity of the IGL neurons (PEKALA et al. 2007).

In previous studies, we have demonstrated the existence of isoperiodic ultradian oscillations in the neuronal firing of the rat IGL (LEWANDOWSKI et al. 1999) which are suggested as a basic activity of this structure as well as the whole neuronal mechanism of CTS (LEWANDOWSKI \& BLASIAK 2004). However, the cholinergic influence on this rhythmic bursting is unknown.

Therefore, the aim of the present study was to determine whether and how the intravenous injection of atropine - the antagonist of muscarinic cholinergic receptors, affects the rhythmic oscillation in the activity of intergeniculate leaflet neurons.

\section{Material and Methods}

The experiments were successfully performed on 10 male Wistar rats weighing 300-400 g, kept on a 12:12 light-dark cycle (light on at 08:00 h), bred in our laboratory. Water and food were available ad libitum. All the animal handling and surgical procedures were carried out in accordance with the European Community Council Directive of 24 November 1986 (86/609/EEC) and Polish national law. The animals were anesthetized with intraperitoneal injection of Urethane $(1.5 \mathrm{~g} / \mathrm{kg}$, dissolved in $2 \mathrm{ml}$ of saline, supplemented later if necessary; SIGMA). The femoral vein was then catheterized for intravenous drug administration and the animals were mounted in a stereotaxic apparatus (ASI). During the experiment, the animal's body temperature was monitored and maintained thermostatically at $37 \pm 0.5^{\circ} \mathrm{C}$. A sagittal incision was made and the upper surface of the skull was exposed and cleaned. After exposing the skull surface, the incisor bar was adjusted until the levels of lambda and bregma were equal. Craniotomies were performed above the level of the IGL and visual areas of the cortex to permit microelectrode penetration into the IGL and implantation of an EEG recording electrode. EKG and EEG signals were monitored to verify the physiological state of the animals.

The extracellular recording of neuronal activity within the IGL (stereotaxic coordinates: AP: -4.5 $\mathrm{mm}, \mathrm{LM}: 3.9 \mathrm{~mm}, \mathrm{DV}: 4.5-5.0 \mathrm{~mm}$ from the bregma) was performed using glass microelectrodes (impedance $5 \mathrm{Mohm}$ ) filled with $2 \mathrm{M} \mathrm{NaCl}$ and $2 \%$ Chicago Sky Blue. An EEG signal from the visual cortex was epidurally recorded with a silver ball electrode. The recording was carried out under constant illumination (300 lux at the animal's eye level). The signal from the electrodes was amplified $(10000 \times$ for MUA; $5000 \times$ for EEG), filtered (0.3-3 kHz for MUA; $1-200 \mathrm{~Hz}$ for EEG) using an Axon Instruments CyberAmp 380, and sampled by Micro $1401 \mathrm{mk}$ II (CED) equipment and software (Spike2) for storage and further analysis.

In each experiment, after achieving baseline activity, Ringer solution (vehicle for atropine) was administrated intravenously. After another 20 minutes of recording, atropine (ATR, Sigma) in a dose of 4 or $8 \mathrm{mg} / \mathrm{kg}$ ( $4 \%$ or $8 \%$ concentration respectively), diluted in the Ringer solution, was infused intravenously. Only one infusion of the control solution and one of the drug was performed on the same animal.

At the end of the experiment, a current of $-5 \mu \mathrm{A}$ was passed through the recording electrode for 3.5 min in order to mark the exact position of the tip of the electrode.

During the experiment, rate-meter histograms of IGL neuronal activity (1-s bins) were generated. To determine the period of rhythmic bursting observed in the IGL, Fast Fourier Transforms were applied to 1200 -s intervals in the rate-meter histograms before vehicle infusion, and directly before and immediately after drug application.

All values were tested for a normal distribution using Shapiro-Wilk's W test (normality was assumed for $W$ significance of $\mathrm{P}>0.05$ ). The changes induced by drug application were analyzed by a one-way repeated-measure ANOVA. Statistical significance was judged at $\mathrm{P}<0.05$.

All the descriptive statistical data are given as means \pm S.E.M. Statistical calculations including Fast Fourier Transforms, autocorrelation function analysis and generation of the histograms of firing frequency distribution were made using Statistica software (StatSoft).

\section{Results}

After recording the baseline of slow bursting neuronal activity in the IGL (at least $20 \mathrm{~min}$ ), Ringer solution was intravenously injected into the femoral vein. As the administration of the vehicle alone caused no changes in the pattern of neuronal activity $(\mathrm{P}=0.995, \mathrm{~F}=0.00004)$ (Figs 1,3$)$, after another $20 \mathrm{~min}$ of recording, the muscarinic cholinergic receptor antagonist - atropine, was ap- 


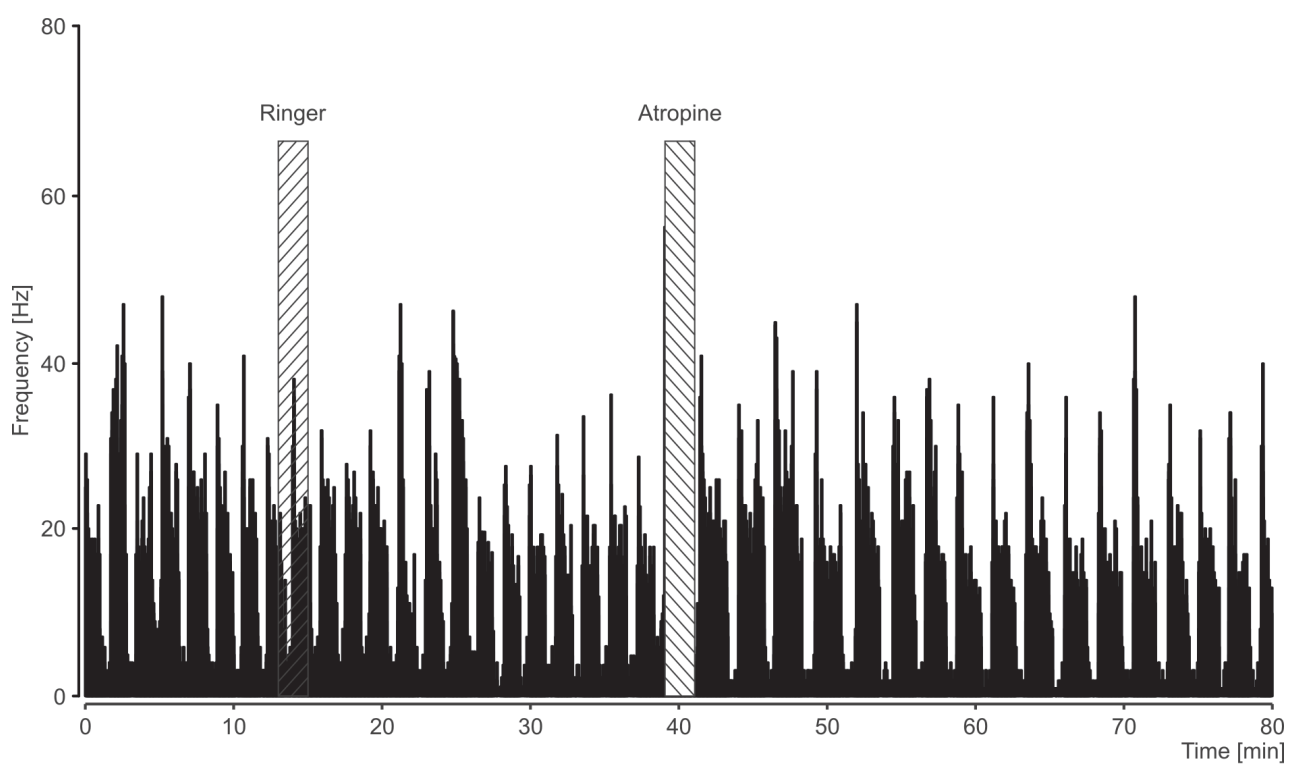

Fig. 1. Firing rate histogram showing rhythmic, slow bursting activity of IGL neurons. Vertical bars indicate the time of i.v. injection of vehicle and atropine. Bin size $=1 \mathrm{~s}$.

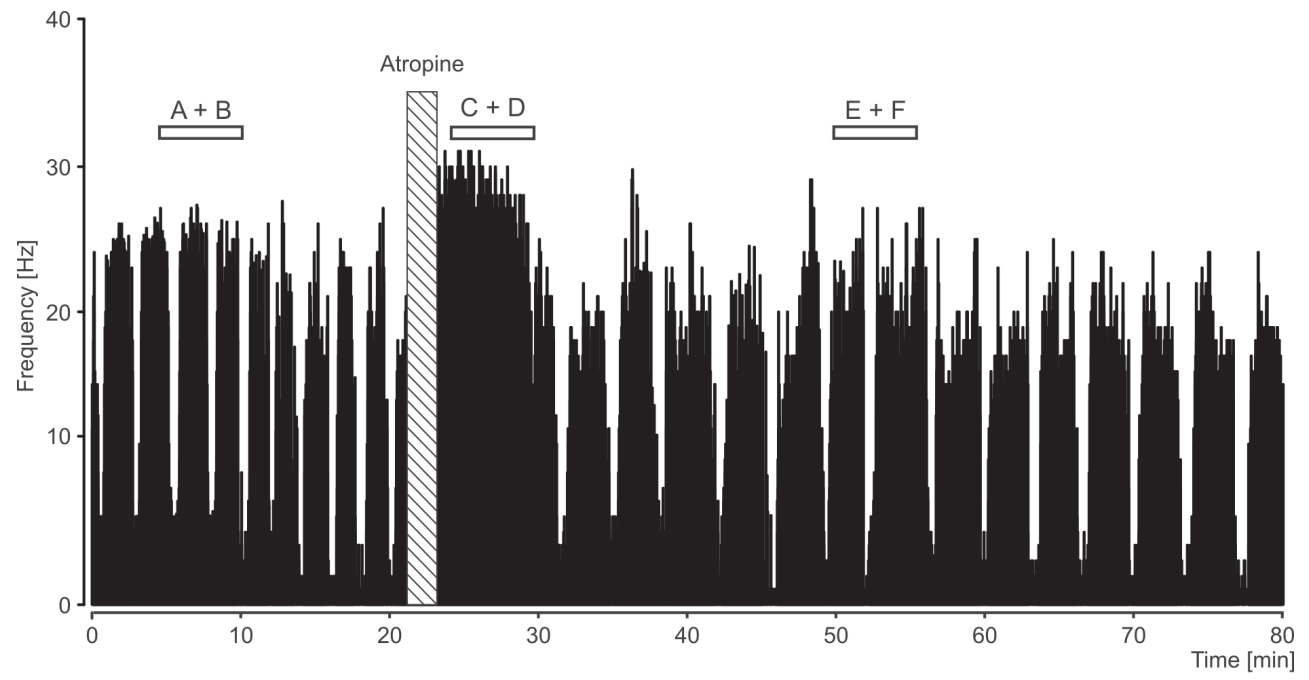

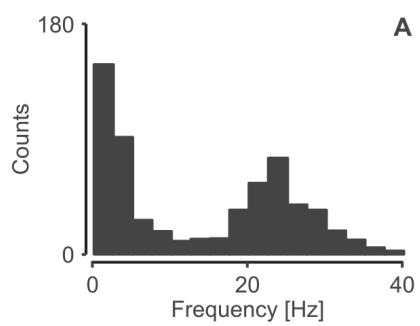

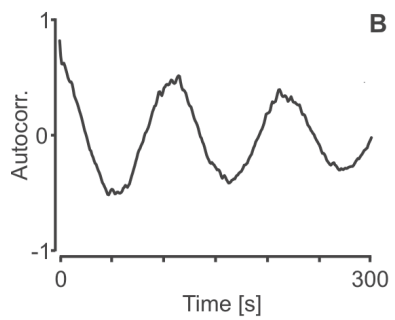

A 180$]$ C
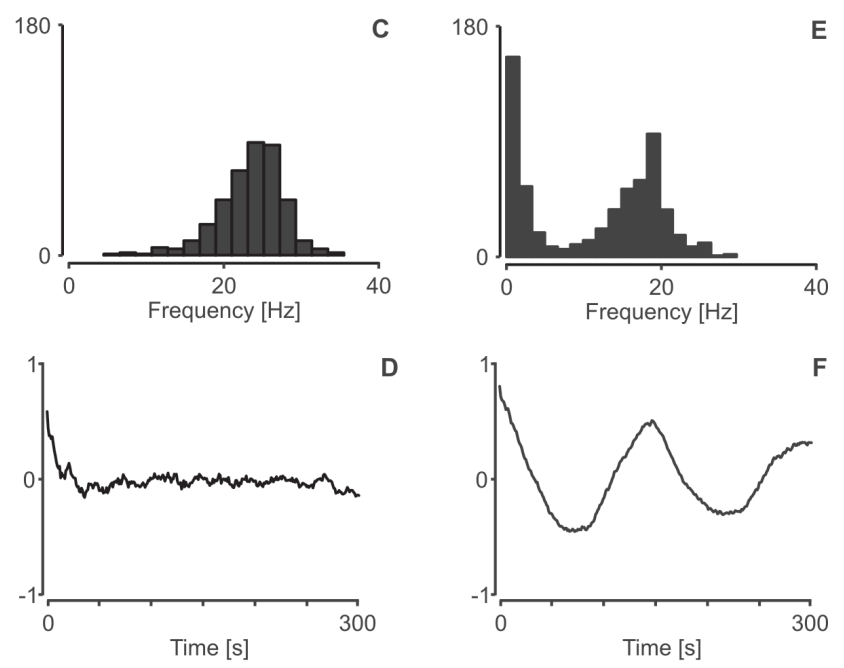

Fig. 2. (Top) Firing rate histogram of the IGL neuronal activity before and after drug application (vertical bar). Bin size $=1 \mathrm{~s}$. Horizontal, hollow bars indicate intervals for which the distribution of firing frequencies and the autocorrelation functions were estimated (Bottom) A, C, E- histograms showing the distribution of the firing frequencies of IGL neurons before (A) and after $(\mathrm{C}, \mathrm{E})$ drug application. Bin size $=2 \mathrm{~Hz}$. B, D, F - curves of the autocorrelation function of IGL neuronal activity before (B) and after $(D, F)$ injection of atropine. 
A.

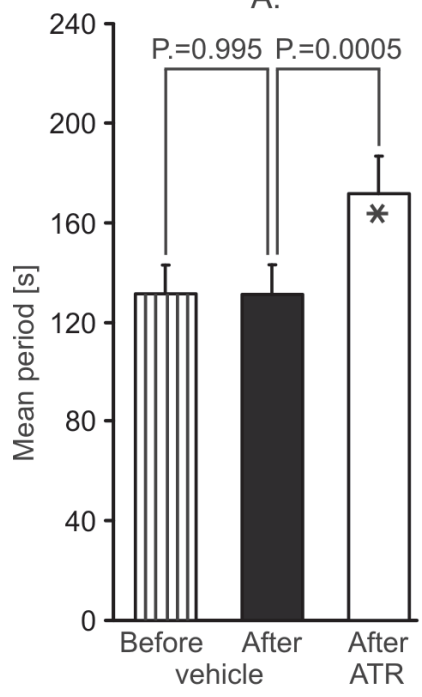

B.

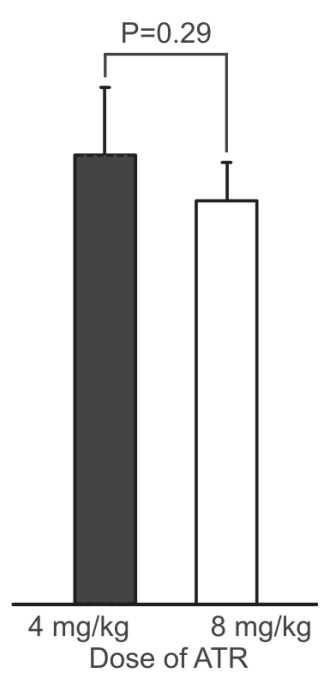

Fig. 3. Bar graph showing the mean periods of neuronal oscillation within the IGL. A - vertically dashed bar indicates the mean period before vehicle injection (baseline); solid bar - the mean period after vehicle injection (control); hollow bar - the mean period after drug injection. B - solid bar indicates the mean period after atropine injection in a dose of $4 \mathrm{mg} / \mathrm{kg}$; hollow bar - the mean period after an injection in a dose of $8 \mathrm{mg} / \mathrm{kg}$. Asterisk shows statistically significant difference. Each bar shows the mean period \pm S.E.M.

plied. In all experiments, after atropine injection, the period of observed oscillation became longer $(\mathrm{P}=0.0005, \mathrm{~F}=31.27$ ) (Figs 1, 2, 3). In 5 cases, immediately after drug injection, a temporary disappearance (no more than $600 \mathrm{~s}$ ) of rhythmic slow bursting activity was observed (Fig. 2). During this period, neuronal firing was characterized by a flat curve of the autocorrelation function and by an unimodal distribution of frequencies in the firing rate histogram (Fig. 2C, D). After this transient disturbance a recovery of the slow bursting activity was observed, but the period of neuronal oscillation, as in the remaining cases, was significantly longer than before drug application (Figs 1, 2E, F, $3 \mathrm{~A})$. After drug application, recording was carried out in a few cases even up to 5 hours and no recovery to the previous period's length was observed.

The period's broadening did not differ statistically between the two applied doses $(\mathrm{P}=0.29$, $\mathrm{F}=1.26$ ). However, after injection of ATR in a dose of $8 \mathrm{mg} / \mathrm{kg}$, the increase of the mean period of the observed oscillation was smaller (Fig. 3B).

The injection of atropine had no statistically significant effect on the mean firing rate $(\mathrm{P}=0.45$, $\mathrm{F}=0.63$ ).

\section{Discussion}

In the present study, we have clearly demonstrated that intravenous injection of a general mus-

carinic receptor antagonist - atropine - alters the neuronal firing of the oscillating cells within the rat IGL. In all investigated cases, the blockade of muscarinic receptors caused an enlargement of recorded ultradian oscillations. In addition, in half of the cases, we observed temporary disturbances of the rhythmic pattern of neuronal activity. Interestingly similar effects on the neuronal oscillations were previously observed after blockade of $\mathrm{GABA}_{\mathrm{A}}$ receptors by bicuculline (BLASIAK \& LEWANDOWSKI 2004).

A significant limitation of the present study is that general administration of atropine does not determine the precise site of the action of the drug. Therefore, in our discussion we can only suggest the probable locus of atropine effect.

The work by MOORE and SPEH (1993) has demonstrated that virtually all IGL neurons are GABA-ergic and that GABA is colocalized with enkephalin in the population of neurons projecting to the contralateral IGL, and with neuropeptide Y in the population of neurons projecting to the $\mathrm{SCN}$. They showed also that most of the SCN cells are GABA-producing and proposed to consider GABA as the principal neurotransmitter of the circadian system. On the basis of this anatomical study we can consider the action of atropine on GABAergic neurons.

Central mAChRs are most frequently found at presynaptic sites and their activation leads to the modulation of neurotransmitter release. They have been known to regulate GABAergic transmission with diverse effects: acetylcholine, as well as muscarinic receptor agonists, can either enhance or suppress GABA release. There are some data indicating that activation of $\mathrm{mAChRs}$ stimulates the release of GABA in rat substantia nigra, globus pallidus or neostriatum (HARSING Jr \& ZIGMOND 1998; KAYADJANIAN et al. 1994; KAYADJANIAN et al. 1997). However, in rat cortex, corpus striatum or midbrain dopaminergic neurons (GRILLNER et al. 2000; HASHIMOTO et al. 1994; MARCHI et al. 1990) it is able to inhibit GABAergic synaptic transmission and GABA release. It is interesting to note that these opposing effects were antagonized by atropine. The nature of the response was dependent, first of all, on the receptor subtypes involved, but there were also essential discrepancies between different brain regions and effective doses of muscarinic drugs required to obtain modulatory effects.

There is much data demonstrating the distribution of mAChRs and showing the action of the cholinergic agents in many regions of CNS. PLUMMER et al. (1999) have identified specific muscarinic receptors for acetylcholine in the rat LGN, although they do not distinguish IGL from 
the lateral geniculate complex. They have revealed especially dense immunoreactivity in the entire LGN for a $\mathrm{m} 2$ receptor subtype known as an autoreceptor or heteroreceptor, regulating the release of neurotransmitters. Additionally, they have demonstrated that neurons immunopositive for the $\mathrm{m} 2$ receptor have a somatodendritic morphology of internurons. Because IGL cells involved in the observed oscillations form an interconnected network of GABAergic interneurons (similar to that formed by GABAergic cells in the SCN) (BLASIAK \& LEWANDOWSKI 2004), it can be presumed that the $\mathrm{m} 2$ receptor may be the predominant muscarinic receptor subtype associated with these inhibitory neurons in the IGL, as in the LGN and the entire thalamus. Furthermore, there are numerous studies describing the suppressed effect of cholinergic modulation on the inhibitory action of interneurons (MCCORMICK \& PAPE 1988; MCCORMICK 1992). Therefore, we suggest that the application of atropine, by acting on the $\mathrm{m} 2$ receptor subtype, could have decreased the release of GABA and consequently suppressed the action of this neurotransmitter on the IGL bursting cells, thus inducing the longer action of neuronal firing. This kind of atropine action might be therefore consistent with the similar effect of bicuculline on IGL oscillations, suggesting a close relationship between the cholinergic and the GABAergic system within this nucleus.

Acetylcholine acting on muscarinic receptors also modulates other types of neurotransmission, such as dopaminergic or glutaminergic (FORSTER $\&$ BLAHA 2003). Activation of the mAChRs located on glutaminergic axon terminals in rat hippocampus can inhibit the release of glutamate (Glu) and this effect is blocked by atropine (MARCHI et al. 1989). There is anatomical evidence showing the localization of GluRs mRNAs in the rat IGL (SATO et al. 1993). Electrophysiological data from our laboratory (BLASIAK et al. 2007; PEKALA et al. 2007) has shown responsiveness of the IGL cells to Glu, therefore confirming the existence of Glu innervation of the IGL. For this reason, another possible locus for atropine effects is a blockade of mAChRs located on glutamatergic nerve terminals and excitation of Glu release.

Because of the systemic injection of the drug, we could not exclude affecting the muscarinic receptors of neurons in other brain regions. It is possible that the observed effect is due to the blockade of mAChRs in the structures that simultaneously receive cholinergic innervations and whose neurons project to the IGL. What is even more probable, the observed amplification of the oscillations in extracellular activity of the IGL cells could be a consequence of altered neuronal activity of afferent structures and direct action of atropine on the IGL cells.
In half of the cases, immediately after injection of atropine, we noticed transient disturbances in the rhythmic neuronal activity. This effect was neither dependent on the applied dose of the drug nor on the circadian time of injection. Interestingly, this disappearance of rhythmic slow bursting in IGL activity appears after intracerebroventricular infusion of bicuculline or picrotoxin and also after a shift from dark to light (BLASIAK \& LEWANDOWSKI 2004; LEWANDOWSKI et al. 2000). An injection of atropine can enhance ACh release by blockading ACh autoreceptors in mesencephalic reticular formation (MRF) and on the axon terminals (BAGHDOYAN et al. 1998; MOOR et al. 1995; ROTH et al. 1996). Therefore, it could increase the action of ACh on nicotinic receptors, as their activation requires higher concentrations of ACh than do muscarinic receptors (LEWANDOWSKI et al. 1993). Activation of MRF (due to an atropine injection or a light pulse) has been known to trigger a state of arousal accompanied by desynchronization of EEG. Perhaps this temporary tonic firing mode of IGL neurons is the time required to stabilize the modulatory action of ACh released from MRF cells. The fact that it appears only in $50 \%$ of our experiments could be dependent on the physiological state of an animal. However, this assumption should be tested in successive experiments.

The present results suggest that the oscillatory firing of IGL cells can be modulated by cholinergic influences. However, to fully answer the question concerning localization of the site of action of the cholinergic drug and to define which particular receptor subtypes are involved in the observed effect, experiments with local drug application of agents selective for particular ACh receptor subtypes are required.

\section{References}

Baghdoyan H. A., Lydic R., FleEgal M. A. 1998. M2 muscarinic autoreceptors modulate acetylcholine release in the medial pontine reticular formation. J. Pharmacol. Exp. Ther. 286: 1446-52.

BINA K. G., RUSAK B. 1996. Muscarinic receptors mediate carbachol-induced phase shifts of circadian activity rhythms in Syrian hamsters. Brain Res. 743: 202-11.

Blasiak A., PEKala D., Lewandowski M. H. 2007. The responsiveness of the rat intergeniculate leaflet neurons to glutamatergic agonists. J. Physiol. Pharmacol. 58: 669-81.

BLASIAK T., LEWANDOWSKI M. H. 2004. Blockade of GABAA receptors disrupts isoperiodic neuronal oscillations in the intergeniculate leaflet of the rat. Brain Res. 1009: 82-7.

BlasiaK T., SiEJKA S., RAISON S., PEVET P., LEWANDOWSKI M. H. 2006. The serotonergic inhibition of slowly bursting cells in the intergeniculate leaflet of the rat. Eur. J. Neurosci. 24: $2769-80$.

Brauer K., Schober W., Leibnitz L., Werner L., Luth H. J., WINKELMANN E. 1984. The ventral lateral geniculate nucleus of the albino rat morphological and histochemical observations. J. Hirnforsch. 25: 205-36. 
FERGUSON S. A., KENNAWAY D. J., MOYER R. W. 1999 Nicotine phase shifts the 6-sulphatoxymelatonin rhythm and induces c-Fos in the SCN of rats. Brain Res. Bull. 48: 527-38.

Forster G. L., Blaha C. D. 2003. Pedunculopontine tegmental stimulation evokes striatal dopamine efflux by activation of acetylcholine and glutamate receptors in the midbrain and pons of the rat. Eur. J. Neurosci. 17: 751-62.

GRILlNER P., BERRETTA N., BERNARDI G., SVENSSON T. H., MERCURI N. B. 2000. Muscarinic receptors depress GABAergic synaptic transmission in rat midbrain dopamine neurons. Neuroscience 96: 299-307.

HARSING Jr L. G., ZigMOND M. J. 1998. Postsynaptic integration of cholinergic and dopaminergic signals on mediumsized GABAergic projection neurons in the neostriatum. Brain Res. Bull. 45: 607-13.

Hashimoto T., SHu H., KuRIYAma K. 1994. Muscarinic M1 receptor mediated inhibition of GABA release from rat cerebral cortex. Neurochem. Int. 24: 389-94.

HOROWITZ S. S., BLANCHARD J. H., MORIN L. P. 2004. Intergeniculate leaflet and ventral lateral geniculate nucleus afferent connections: An anatomical substrate for functional input from the vestibulo-visuomotor system. J. Comp. Neurol. 474: 227-45.

Kayadjanian N., Gioanni H., Menetrey A., Besson M. J. 1994. Muscarinic receptor stimulation increases the spontaneous [3H] GABA release in the rat substantia nigra through muscarinic receptors localized on striatonigral terminals. Neuroscience 63: 989-1002.

Kayadjanian N., Menetrey A., Besson M. J. 1997. Activation of muscarinic receptors stimulates GABA release in the rat globus pallidus. Synapse 26: 131-9.

Kow L. M., PFAFF D. W. 1984. Suprachiasmatic neurons in tissue slices from ovariectomized rats: electrophysiological and neuropharmacological characterization and the effects of estrogen treatment. Brain Res. 297: 275-86.

LeVEy A. I., HALLANGer A. E., WAINER B. H. 1987. Choline acetyltransferase immunoreactivity in the rat thalamus. J. Comp. Neurol. 257: 317-32.

Lewandow ski M. H., Muller C. M., Singer W. 1993. Reticular facilitation of cat visual cortical responses is mediated by nicotinic and muscarinic cholinergic mechanisms. Exp. Brain Res. 96: 1-7.

LEWANDOWSKI M. H., BLASIAK T. 1999. The effect of brainstem stimulation on the evoked potentials in the intergeniculate leaflet. Brain Res. 827: 139-42.

LeWANDOWSKi M. H., Blasiak T., DOMOSLawski J., WOLKOWSKA A. 2000. Ultradian rhythmic neuronal oscillation in the intergeniculate leaflet. Neuroreport 11: 317-21.

LEWANDOWSKi M. H., BLASIAK T. 2004. Slow oscillation circuit of the intergeniculate leaflet. Acta Neurobiol. Exp. (Wars). 64: 277-88.
LiU C., GILLETTE M. U. 1996. Cholinergic regulation of the suprachiasmatic nucleus circadian rhythm via a muscarinic mechanism at night. J. Neurosci. 16: 744-51.

MARchi M., Bocchieri P., Garbarino L., RAITERI M. 1989. Muscarinic inhibition of endogenous glutamate release from rat hippocampus synaptosomes. Neurosci. Lett. 96: 229-34.

MARCHI M., SANGUINETI P., RAITERI M. 1990. Muscarinic receptors mediate direct inhibition of GABA release from rat striatal nerve terminals. Neurosci. Lett. 116: 347-51.

MCCORMICK D. A., PAPE H. C. 1988. Acetylcholine inhibits identified interneurons in the cat lateral geniculate nucleus. Nature 334: 246-8.

MCCORMICK D. A. 1992. Cellular mechanisms underlying cholinergic and noradrenergic modulation of neuronal firing mode in the cat and guinea pig dorsal lateral geniculate nucleus. J. Neurosci. 12: 278-89.

Moga M. M., Moore R. Y. 1997. Organization of neural inputs to the suprachiasmatic nucleus in the rat. J. Comp. Neurol. 389: 508-34.

Moor E., DeBoer P., Auth F., Westerink B. H. 1995. Characterisation of muscarinic autoreceptors in the septohippocampal system of the rat: a microdialysis study. Eur. J. Pharmacol. 294: 155-61.

MOORE R. Y., CARD J. P. 1994. Intergeniculate leaflet: an anatomically and functionally distinct subdivision of the lateral geniculate complex. J. Comp. Neurol. 344: 403-30.

MoORE R. Y., SPEH J. C. 1993. GABA is the principal neurotransmitter of the circadian system. Neurosci. Lett. 150: 112-6.

MoORE R. Y., SPEH J. C., LEAK R. K. 2002. Suprachiasmatic nucleus organization. Cell Tissue Res. 309: 89-98.

PeKala D., Blasiak A., Lewandowski M. H. 2007. The influence of carbachol on glutamate-induced activity of the intergeniculate leaflet neurons-in vitro studies. Brain Res. 1186: $95-101$.

Plummer K. L., ManNing K. A., LeVey A. I., ReEs H. D., UHLRICH D. J 1999. Muscarinic receptor subtypes in the lateral geniculate nucleus: a light and electron microscopic analysis. J Comp. Neurol. 404: 408-25.

Roth M. T., FleEgal M. A., Lydic R., Baghdoyan H. A. 1996. Pontine acetylcholine release is regulated by muscarinic autoreceptors. Neuroreport 7: 3069-72.

Sato K., Kiyama H., Tohyama M. 1993. The differential expression patterns of messenger RNAs encoding non-Nmethyl-D-aspartate glutamate receptor subunits (GluR1-4) in the rat brain. Neuroscience 52: 515-39.

WEBER E. T., REA M. A. 1997. Neuropeptide Y blocks lightinduced phase advances but not delays of the circadian activity rhythm in hamsters. Neurosci. Lett. 231: 159-62. 